\title{
A Comparative Evaluation of Human Gingival Tissue Response to Silk \& M-Polytetrafluoroethylene Sutures - A Clinico-Histological Study
}

\author{
Trupti Bhaskar Naykodi¹, Aditya Kiran Shinde ${ }^{2}$ \\ ${ }^{1}$ Department of Periodontics, MGM Dental College \& Hospital, Kamothe, Navi Mumbai, Maharashtra, India. \\ 2 Department of Conservative Dentistry, MGM Dental College \& Hospital, Kamothe, Navi Mumbai, Maharashtra, India.
}

\section{ABSTRACT}

\section{BACKGROUND}

Sutures require specific physical characteristics and properties such as good tensile strength, dimensional stability, lack of memory, knot security and sufficient flexibility to avoid damage to the oral mucosa. The strength and adherence of the sutured tissue increases over time. Tissue reaction characteristics involve varying degree of inflammatory reactions. Therefore, the purpose of this study was to assess clinically and histologically human gingival tissue reaction to silk \& $\mathrm{m}$ - polytetrafluoroethylene (m-PTFE) sutures in periodontal surgical procedures.

\section{METHODS}

The present study is a prospective clinical randomised split mouth study. A total of 15 patients of both sexes were included in the study. All the patients were provided with thorough scaling and root planing before the commencement of the study. The patients were re-evaluated at 4 weeks and sutures were placed in the surgical area where there was a need for excision of gingival tissue as a part of routine periodontal surgery. After placement of sutures, the change of bite, change of slack, clinical changes in plaque index, modified gingival index \& sulcus bleeding index and the histological changes in mean thickness of the peri sutural epithelial sleeve, proportion of inflammatory cells to peri sutural epithelial cells, diameter of the connective tissue inflammatory infiltrate (measured in $\mathrm{mm}$ ) from the periphery of the epithelialization of the sutures from the insertion day (day 0 ) to the day of scheduled surgery (day 7) were recorded.

\section{RESULTS}

Silk sutures presented an increase in the change of bite and change of slack of the suture loop than m-PTFE. Diameter of the connective tissue infiltrate was greater around the multifilament suture (SILK) as compared to the monofilament suture (mPTFE) though the difference was not statistically significant. (P-value $=0.321$ ). Monofilament suture (m-PTFE) showed the least amount of inflammatory infiltrate around the suture track. The proportion of inflammatory cells to epithelial cells was statistically not significant between the two suture materials $(\mathrm{P}$-value $=0.82$ )

\section{CONCLUSIONS}

Though the clinical and histological parameters are statistically non-significant, mpolytetrafluoroethylene has shown better results compared to silk. Silk sutures cause a more extensive inflammatory tissue reaction in an environment characterized by moisture and infectious potential compared to m-PTFE sutures.

\section{KEY WORDS}

PTFE, Inflammatory Response, Sutures, Gingiva
Corresponding Author: Dr. Trupti Bhaskar Naykodi,

Flat no-1401,

Yugandhara Society,

Plot no-13/14, Sector-8,

Kharghar -410210

Navi Mumbai, Maharashtra, India.

E-mail: truptibnaykodi@gmail.com

DOI: $10.14260 / j e m d s / 2021 / 259$

How to Cite This Article:

Naykodi TB, Shinde AK. A comparative evaluation of human gingival tissue response to silk \& $M$. polytetrafluoroethylene sutures - a clinicohistological study.J Evolution Med Dent Sci 2021;10(17):1213-1218, DOI: 10.14260/jemds/2021/259

Submission 26-10-2020,

Peer Review 23-02-2021,

Acceptance 02-03-2021,

Published 26-04-2021.

Copyright (C) 2021 Trupti Bhaskar Naykodi et al. This is an open access article distributed under Creative Commons Attribution License [Attribution 4.0 International (CC BY 4.0)] 


\section{BACKGROUND}

A suture is a biomaterial device either natural or synthetic, used to ligate blood vessels or approximate tissues. ${ }^{1}$ Thus its major function is to bring and hold tissues together following separation by surgery or trauma. ${ }^{2}$ The first synthetic suture materials produced in 1940's were nylon and polyester. Thereafter polyethylene and polypropylene were developed. ${ }^{3}$

Biological responses to suture materials may include varying degrees of inflammatory reaction ${ }^{4}$ related to the physio-chemical properties of the suture material and to the type and condition of the sutured tissues.5,6 Suturing in dentistry is different from suturing of other parts of the body because of the type of tissues involved, the constant presence of saliva, high tissue vascularization, and functions related to speech, mastication and swallowing. Appropriate sutures require specific physical characteristics and properties such as good tensile strength, dimensional stability, lack of memory, knot security and sufficient flexibility to avoid damage to the oral mucosa. The strength and adherence of the sutured tissue increases over time and investigators have noted that a significant increase in the flap strength is achieved between 1 and 2 weeks.6,7

Suture materials are evaluated in three main ways: physical characteristics, handling characteristics and tissue reaction characteristics. Physical characteristics include physical structure, capillarity, diameter, breaking and knot strength, elasticity and memory. Handling characteristics such as knot tying and knot slippage which are affected by the coefficient of friction. Tissue reaction characteristics involve varying degree of inflammatory reactions. ${ }^{8} \mathrm{An}$ advantage of absorbable sutures is that generally they do not require removal and of non-absorbable suture materials is that they elicit little tissue reaction. ${ }^{9}$ Materials like silk, nylon, steel, catgut, polyglycolic (PGA), polylactic acid (PLA) derivatives, polytetrafluorethylenes are being used for the post-operative closure of flaps. These are available in monofilament or multi filamentous threads which can be resorbable or nonresorbable. ${ }^{10}$ Silk is available in braided form. It is made of silkworm larvae. It loses its strength after two years. It has excellent handling characteristics and knot security. The main drawbacks of these suture are coating that reduces the knot security, incites tissue reaction, infection and "capillarity. ${ }^{11 "}$

PTFE suture is a monofilament, non-resorbable suture manufactured from $100 \%$ polytetrafluoroethylene (PTFE) polymer. The suture is undyed and contains no additives. PTFE has shown minimal tissue reaction in clinical trials. The Golnit $^{\mathrm{TM}}$ PTFE Suture is not absorbed or subjected to weakening by tissue enzymes, and does not degrade in the presence of infection. The Golnit ${ }^{\mathrm{TM}}$ non-absorbable PTFE suture is intended for use in the approximation and ligation of soft tissue in the oral cavity (including fixation of barrier membranes), plastic, peripheral vascular and general surgery. However, there are very few studies determining the human gingival tissue response to these suture materials in periodontal surgical procedures and also there is dearth of studies regarding the effect of simulated oral conditions on the tensile strength of these suture materials over a period of time.

\section{Objectives}

1) To compare \& evaluate significance of clinical parameters like change of bite, change of slack, Plaque index, modified gingival index \& sulcus bleeding index from insertion day (day 0 ) to the day of scheduled surgery (day 7),

2) To compare \& evaluate significance of histological parameters in:

- Mean thickness of the peri sutural epithelial sleeve

- Proportion of inflammatory cells to peri sutural epithelial cells.

- Diameter of the connective tissue inflammatory infiltrate (measured in $\mathrm{mm}$ ) from the periphery of the epithelialization of the sutures.

\section{METHODS}

\section{Study Population}

The present study is a prospective clinical randomised split mouth study. The test subjects were recruited from the patients visiting the outpatient division of the Department of Periodontics, undergoing periodontal treatment, of the D Y Patil University School of Dentistry, Navi Mumbai. A total of 15 patients with moderate to severe periodontitis were randomly selected among them. Patients of both the sexes in the age group of 30 to 50 years were included in the study. An ethical clearance was obtained prior to commencement of the study. The study was conducted between January 2015 and June 2016 for about 18 months.

Systemically healthy patients, patients requiring excision of gingival tissue as a part of routine periodontal surgery, with no previous periodontal surgery in that area in the past 12 months and diagnosed with generalised chronic moderate to severe periodontitis were included in the study. Patients with general contraindications for periodontal surgery, medically compromised subjects, pregnant women, subjects who were on antibiotics or non-steroidal anti-inflammatory drugs (NSAIDs) or immunosuppressant medication within the last six months, subjects with acute illnesses or acute oral lesions, smokers and smokeless tobacco users, chronic alcoholics and patients with poor compliance were excluded from the study.

\section{Suture Materials Used}

Two suture materials of 3 - 0 gauge were selected for this study based on their usage in periodontal surgery:

- $\quad$ Non-resorbable Silk suture (Ethicon, Mersilk ${ }^{\mathrm{TM}}$, Johnson \& Johnson Ltd, India)

- $\quad$ Non-resorbable m-PTFE suture (Golnit ${ }^{\mathrm{TM}}$, Ukraine)

\section{Informed Consent}

Patients were explained about all the aspects of the study and an informed consent was obtained from the patients before any procedure was performed.

\section{Treatment Protocol}

\section{Phase I Therapy}

All the patients were provided with thorough scaling and root planing before the commencement of in vivo phase of the 
study. The therapeutic endpoint was defined as clean root surface devoid of visible or clinically detectable remnants of biofilm or calculus. The patients were re-evaluated at 4 weeks following phase I therapy and sutures were placed in the surgical area where need for excision of gingival tissue as a part of routine periodontal surgery was present.

\section{Placement of Sutures (at 0 Days)}

A 7-day observation period was considered adequate for the present study as stated by Leknes K.N et al. 2005. Seven days before the scheduled excision procedure, sutures were placed in the area planned for surgical removal with internal bevel incision under local anaesthesia (2\% lignocaine with 1:80,000 adrenaline). The surgical area receiving a particular suture material was decided by simple randomization by picking up strips of paper with names of suture material written on it from a box. Single interrupted suture was placed in the gingival tissues planned for excision. Each suture was firmly adapted with a buccally placed surgical knot. The patients were advised to maintain plaque control using $0.2 \%$ chlorhexidine solution and to avoid brushing the surgical area during the experimental period. Entry and exit of the suture points were located at approximately $3 \mathrm{~mm}$ from the tip of the interdental papilla. Clinical pictures were documented for suture insertion. All sutures were placed by the same clinician.

\section{Specimen Handling}

Once the gingival tissue was excised it was immediately transferred to formalin solution and preserved up to $24 \mathrm{hrs}$, from the time of retrieval. Harvested tissues were immersed in a formaldehyde fixative, cleansed in water, then dehydrated in ethyl alcohol, and embedded in paraffin. The specimens were oriented with the suture in situ, serial sections were made parallel to the tissue surface. Hence, the sutures had a crosssectioned profile. Each section was mounted on glass slides and stained with haematoxylin and eosin ( $\mathrm{H} \& \mathrm{E})$ and examined under optical microscope.

\section{Statistical Analysis}

The data was statistically analysed in SPSS software. The test of normality was carried out to test whether data follows normality or not. K-S (Kolmogorov-Smirnova) and S-W (Shapiro-Wilk) tests were used, to test the normality. Since the P-value for one or both the test, was greater than 0.05 for all the parameters, we used independent T-test to compare the significance of difference between the means of these parameters. In the histological section, grid points were located on leukocyte like cells and epithelial cells, and the number of epithelial cell and inflammatory cell densities were calculated. One more comparison was done between the proportions of inflammatory cells to epithelial cells. It was also used as a parameter for comparisons. All clinical and histometric data were tabulated and total subject mean and standard deviation (S. D) were calculated.

\section{RESULTS}

\section{Intra-Group Comparison}

The changes in the clinical parameters from 0 to 7 days for both the suture materials are described below, the mean and standard deviation values for plaque index, gingival index and sulcus bleeding index, change of bite and change of slack at 0 days and at 7 days for silk and m-PTFE are shown in Table 1, 2 respectively.

\begin{tabular}{|c|c|c|c|c|c|c|c|}
\hline & & Mean & $\mathbf{N}$ & Std. Deviation & $\begin{array}{l}\text { T-Test } \\
\text { Value }\end{array}$ & Df & P-Value \\
\hline \multirow{2}{*}{ PI } & 0 days & 1.1867 & 15 & 0.48678 & \multirow{2}{*}{4.190} & \multirow{2}{*}{14} & \multirow{2}{*}{0.001} \\
\hline & 7 days & 0.8933 & 15 & 0.38073 & & & \\
\hline \multirow{2}{*}{ GI } & 0 days & 2.3200 & 15 & 0.52126 & \multirow{2}{*}{12.754} & \multirow{2}{*}{14} & \multirow{2}{*}{0.000} \\
\hline & 7 days & 1.1733 & 15 & 0.31728 & & & \\
\hline \multirow{2}{*}{ SBI } & 0 days & 0.8980 & 15 & 0.53034 & \multirow{2}{*}{7.850} & \multirow{2}{*}{14} & \multirow{2}{*}{0.000} \\
\hline & 7 days & 1.1667 & 15 & 0.48795 & & & \\
\hline \multirow{2}{*}{ CB } & 0 days & 0.5133 & 15 & 0.06399 & \multirow{2}{*}{-9.280} & \multirow{2}{*}{14} & \multirow{2}{*}{0.000} \\
\hline & 7 days & 0.6667 & 15 & 0.04880 & & & \\
\hline \multirow{2}{*}{$\mathrm{CS}$} & 0 days & 1.2333 & 15 & 0.41690 & \multirow{2}{*}{-7.872} & \multirow{2}{*}{14} & \multirow{2}{*}{0.000} \\
\hline & 7 days & 2.3333 & 15 & 0.48795 & & & \\
\hline \multicolumn{8}{|c|}{$\begin{array}{c}\text { Table 1. Comparison of O Day Values Against } 7 \text { Day Values in Silk- } \\
\text { Plaque Index (PI), Gingival Index (GI), Sulcus Bleeding Index (SBI), } \\
\text { Change in Bite (CB) and Change in Slack (CS) }\end{array}$} \\
\hline
\end{tabular}

The difference in plaque index values for silk $(\mathrm{P}=0.001)$ and m-PTFE (0.00) from 0 to 7 days was statistically significant. The difference in gingival index values for silk $(\mathrm{P}=$ $0.00)$ and m-PTFE $(P=0.00)$ from 0 to 7 days was statistically significant. The difference in Sulcus Bleeding Index values for silk $(P=0.00)$ and $m$-PTFE $(P=0.001)$ from 0 to 7 days was statistically significant. The difference in change of bite for silk $(\mathrm{P}=0.00)$ and $\mathrm{m}$-PTFE $(1.0)$ from 0 to 7 days was statistically non-significant. The difference in change of slack for silk $(\mathrm{P}=$ $0.00)$ and $m$-PTFE $(P=0.00)$ from 0 to 7 days was statistically non-significant.

\begin{tabular}{|c|c|c|c|c|c|c|c|}
\hline & & Mean & $\mathbf{N}$ & Std. Deviation & T-Test Value & Df & P-Value \\
\hline \multirow{2}{*}{ PI } & 0 days & 1.4200 & 15 & 0.42122 & \multirow{2}{*}{5.611} & \multirow{2}{*}{14} & \multirow{2}{*}{0.000} \\
\hline & 7 days & 1.2267 & 15 & 0.40790 & & & \\
\hline \multirow{2}{*}{ GI } & 0 days & 2.2133 & 15 & 0.47789 & \multirow{2}{*}{11.386} & \multirow{2}{*}{14} & \multirow{2}{*}{0.000} \\
\hline & 7 days & 1.1600 & 15 & 0.16388 & & & \\
\hline \multirow{2}{*}{ SBI } & 0 days & 0.8980 & 15 & 0.53034 & \multirow{2}{*}{4.008} & \multirow{2}{*}{14} & \multirow{2}{*}{0.001} \\
\hline & 7 days & 1.0767 & 15 & 0.48802 & & & \\
\hline \multirow{2}{*}{ СВ } & 0 days & 0.4933 & 15 & 0.07988 & \multirow{2}{*}{0.000} & \multirow{2}{*}{14} & \multirow{2}{*}{1.000} \\
\hline & 7 days & 0.4933 & 15 & 0.05936 & & & \\
\hline \multirow{2}{*}{ CS } & 0 days & 0.2667 & 15 & 0.45774 & \multirow{2}{*}{-1.871} & \multirow{2}{*}{14} & \multirow{2}{*}{0.082} \\
\hline & 7 days & 0.4667 & 15 & 0.51640 & & & \\
\hline \multicolumn{8}{|c|}{$\begin{array}{l}\text { Table 2. Comparison of } 0 \text { Day Values Against } 7 \text { Day } \\
\text { Values in m-PTFE Plaque Index, Gingival Index, Sulcus } \\
\text { Bleeding Index, Change in Bite and Change in Slack }\end{array}$} \\
\hline
\end{tabular}

\section{Inter-Group Comparison (Table 3)}

The difference in plaque index values between silk and $\mathrm{m}$ PTFE was statistically non-significant. $(P=0.211)$. The difference in gingival index values between silk and m-PTFE was statistically non-significant $(\mathrm{P}=0.475)$. The difference in sulcus bleeding index values between silk m-PTFE was statistically non-significant. $(P=0.121)$. The difference in change of bite between silk and m-PTFE was statistically significant $(\mathrm{P}=0.00)$. The difference in Change of Slack for silk and $\mathrm{m}$-PTFE was statistically significant. $(\mathrm{P}=0.00)$

\section{Histological Findings}

Microscopic evaluation of the histopathological slides revealed that the suture materials were seen embedded in the sections. 
In certain cases, the sutures were lost during processing. However, the suture track could be seen in such sections.

At 7 days, well demarcated epithelial ingrowth along the suture track was observed in some sections of the suture. In some cases, the invagination of epithelium followed the entire suture loop. In many sections, no evidence of peri sutural epithelium could be seen regardless of the suture material.
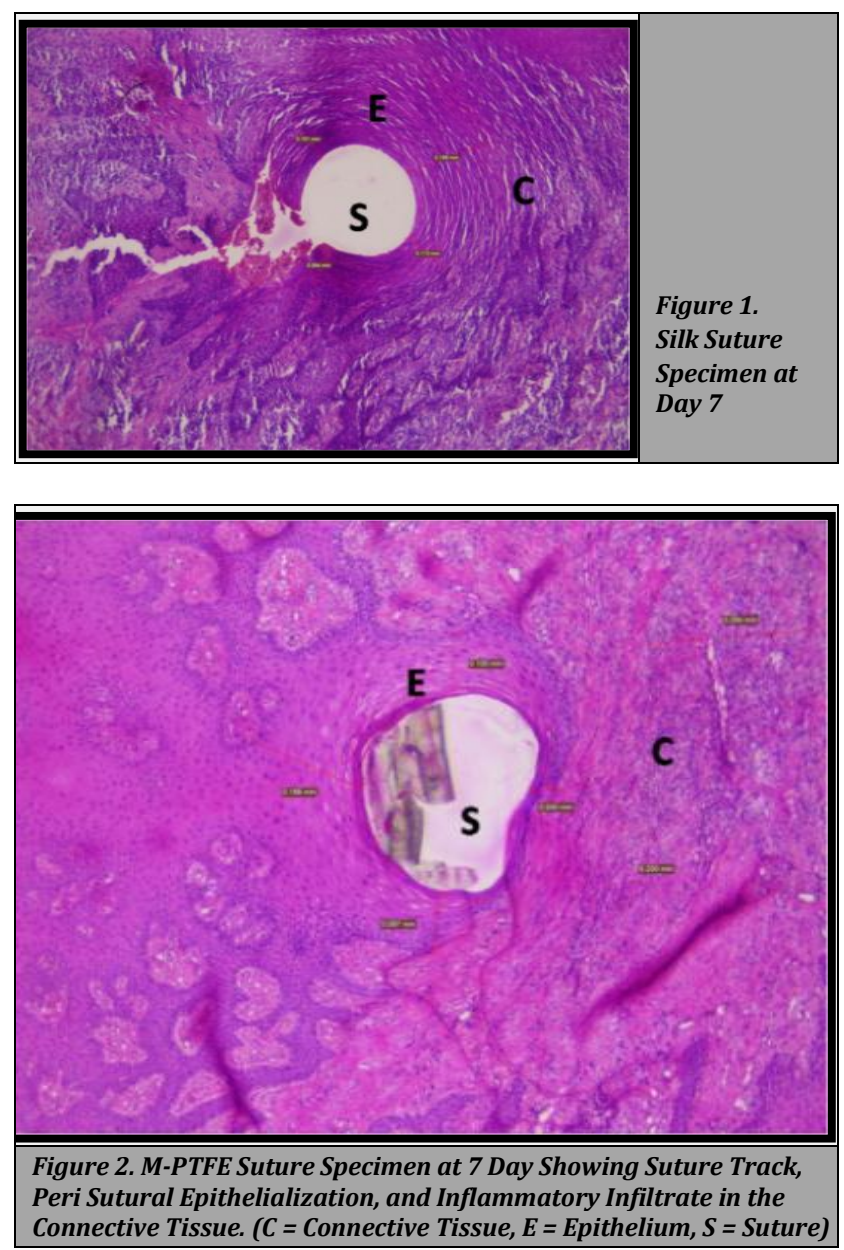

Histological presence of inflammatory cells showed an evident peri sutural connective tissue response. In general, the tissue response varied from large proportion of inflammatory infiltrate to dominance of granulation tissue. Normal connective tissue elements were absent next to the connective tissue. Peripherally, inflammatory cells were seen between connective tissue elements and in the outer surrounding area, fewer inflammatory cells were observed. Sutures which did not show complete epithelialization could be considered as a definite inflammatory response in connective tissue.

The multifilament suture material silk showed a more severe inflammatory response as compared to the monofilament material m-PTFE. The inflammatory infiltrate was denser perisuturally around the multifilament sutures with less density of collagen fibres and other connective tissue elements per unit area. Among the monofilament suture, PTFE showed the least amount of inflammatory infiltrate adjacent to the suture track. Peripherally, the connective tissue was more organized in the PTFE as compared to silk.

\section{Histological Analysis (Table 3)}

At 7 days, the thickness of the peri sutural epithelial sleeve ranged from $0.06 \mathrm{~mm}$ to $0.17 \mathrm{~mm}$ in silk group and from 0.04 $\mathrm{mm}$ to $0.15 \mathrm{~mm}$ in $\mathrm{m}$-PTFE group. Statistically no significant difference was evaluated. $(\mathrm{P}=0.883)$ At 7 days, the diameter of the connective tissue inflammatory infiltrate ranged from $0.04 \mathrm{~mm}$ to $0.52 \mathrm{~mm}$ in silk and from 0.05 to $0.42 \mathrm{~mm}$ in $\mathrm{m}$ PTFE group. Statistically no significant difference was evaluated with the diameter of the connective tissue inflammatory infiltrate $(\mathrm{P}=0.321)$. However, it was observed that inflammatory infiltrate was greater around the multifilament sutures compared to monofilament sutures.

At 7 days, the proportion of inflammatory cells to epithelial cells ranged from $0.2 \mathrm{~mm}$ to $2 \mathrm{~mm}$ in silk group, from $0 \mathrm{~mm}$ to $1.6 \mathrm{~mm}$ in $\mathrm{m}$-PTFE group. Statistically no significant difference was evaluated in relation to the proportion of inflammatory cells to epithelial cells $(\mathrm{P}=0.823)$

\begin{tabular}{|c|c|c|c|c|c|c|}
\hline & $\begin{array}{c}\text { Mean } \\
\text { Difference }\end{array}$ & $\mathbf{N}$ & $\begin{array}{c}\text { SE } \\
\text { Difference }\end{array}$ & $\begin{array}{l}\text { T- } \\
\text { Test }\end{array}$ & Df & $\begin{array}{c}\text { P- } \\
\text { Value }\end{array}$ \\
\hline Plaque index & 0.1 & 15 & 0.07803 & 1.282 & 28 & 0.211 \\
\hline Gingival index & 0.09333 & 15 & 0.129 & 0.724 & 28 & 0.475 \\
\hline Sulcus bleeding index & -1.06667 & 15 & 0.20625 & -5.172 & 28 & 0.121 \\
\hline Change of bite & -0.15333 & 15 & 0.02364 & -6.487 & 28 & 0.000 \\
\hline Change of slack & -0.9 & 15 & 0.17593 & -5.116 & 28 & 0.000 \\
\hline $\begin{array}{l}\text { Thickness of peri } \\
\text { sutural epithelial } \\
\text { sleeve }\end{array}$ & 0.00200 & 15 & 0.01344 & 0.149 & 28 & 0.883 \\
\hline $\begin{array}{c}\text { Diameter of } \\
\text { connective tissue } \\
\text { infiltrate }\end{array}$ & 0.52267 & 15 & 0.51722 & 1.011 & 28 & 0.321 \\
\hline $\begin{array}{c}\text { Proportion of } \\
\text { inflammatory cells to } \\
\text { epithelial cells }\end{array}$ & 0.04000 & 15 & 0.17755 & 0.225 & 28 & 0.823 \\
\hline \multicolumn{7}{|c|}{$\begin{array}{l}\text { Table 3. Plaque Index, Gingival Index, Sulcus Bleeding Index } \\
\text { Change of Bite and Change of Slack, Thickness of Perisutura } \\
\text { Epithelial Sleeve, Diameter of Connective Tissue Infiltrate, } \\
\text { Proportion of Inflammatory Cells to Epithelial Cells }\end{array}$} \\
\hline
\end{tabular}

\section{DISCUSSION}

A good suture material is an ideal requisite for a surgical procedure to attain stability of detached tissues for uneventful healing. Hence, suture material should be biocompatible, maintain adequate strength during the period of healing and show minimal reactions. Wound healing (incisional or excisional) comprises of several phases, starting with the inflammatory stage and further progressing through the matrix formation stage to the remodelling stage. ${ }^{12}$ It has been observed that traumatic suture placement may lead to swelling and sometimes rupture of the sutures. Sutures placed in presence of infectious site causes inflammation, leading to delayed and compromised wound healing "process." Several suture materials are available for the treatment of oral wounds. ${ }^{1}$ Braided sutures appear to conduct bacterial migration more easily along the suture track and into the tissue than the monofilament sutures. ${ }^{13,14,15,16}$

This study evaluated inflammatory tissue response of silk and m-PTFE suture materials in human gingival tissues. The study design differed from other studies in two significant respects (1) the removal of sutures would disturb the healing tissues and the contents of the suture track, all sutures were invariably left in situ during histological processing analysis and (2) the histological sections were made parallel to the mucosal surface, allowing the examination of peri sutural 
tissue reactions at specified depths along the suture track. Previous studies have arbitrarily evaluated tissue response to suturing in humans. Hence to improve the evaluation procedure, a methodical recording of histological reactions after suturing was carried out using histometric analysis.

Patient's age, tissue status before suturing and refusal to maintain oral hygiene may contribute to this variation. In this study two suture materials were placed in the same patient aimed at eliminating or minimizing the influence of the intraindividual variations. The evaluation of the human gingival tissue response to silk and m-PTFE was done based on both clinical and histological parameters. Evaluation of clinical parameters change in the slack of the suture loop and bite of the suture were important parameters taken into consideration showing immobilization of wound margins and healing by primary intention. The mean change in slack of the suture loop and change in bite at 7 days was greater for silk than m-PTFE sutures. This indicates that wound stability could not be maintained by silk suture during a healing period of 7 days. ${ }^{13}$ PTFE exhibits high tensile strength and does not weaken when moistened. This was in accordance with the study done by Leknes KN et al. The plaque index (PI) was used as it had more objective definitions of scoring because of the use of disclosing agent to identify the plaque and a more objective definition of each numerical score. Also repeated evaluation of the plaque scores can be seen as a tool to monitor patient compliance.

Comparative evaluation of scores between the two suture materials showed a decline in plaque score in m-PTFE suture. However, no significance was detected statistically $(\mathrm{P}=0.21)$. This was in accordance with a study done by Parirokh "et al. ${ }^{17}$ which showed PVDF sutures had less contaminated surface area than silk sutures at 3, 5 and 7 days. Also, Selvig et al stated in an article that multifilament sutures conducted greater bacterial migration compared to monofilament sutures.

The Gingival Index (GI) used, shows good validity, reliability and ease of use and also demonstrates sufficient sensitivity to distinguish between groups of mild and severe gingivitis. It also gives a quantitative measurement of bleeding scores which is more informative than a dichotomous index of the presence or absence of bleeding on stimulation for research and clinical trials. M-PTFE sutures exhibited reduced inflammation and advanced wound healing at 7 days than did silk. This was in accordance with the study done by Lilly et al. ${ }^{16}$ and Racey et al. ${ }^{18}$ that showed silk sutures, which are multi filamentous, consistently produced greater inflammatory reactions than monofilament sutures in the oral mucosa. However, statistically both the sutures did not detect any significant difference $(\mathrm{P}=0.475)$. The sulcus bleeding index shows areas of gingival sulcus bleeding upon gentle probing as it recognizes and records the presence of early inflammatory gingival disease. Statistically no significant difference was detected $(\mathrm{P}=0.121)$. It was observed that multifilament suture (silk) elicits more inflammatory reaction compared to monofilament suture (m-PTFE). The histological parameters used were as follows -

Thickness of the Peri Sutural Epithelial Sleeve Epithelial ingrowth along the suture track was rapid, and most of the sutures showed complete epithelial lining of the suture channel at $7^{\text {th }}$ day. In some cases, the invagination of the epithelium followed the entire suture loop. During wound healing epithelium does not proliferate deep into connective tissue, hence increase in change of slack over time and lack of tight fit between the suture thread and the surrounding tissue results. Histometric analysis did not detect any statistically significant difference between the two suture materials in relation to thickness of the peri sutural epithelium $(\mathrm{P}=0.883)$. Similar to this study, by Selvig KA et al. ${ }^{4}$ and Leknes KN et al. ${ }^{13}$

\section{Diameter of the Connective Tissue Inflammatory Infiltrate}

Histometric analysis did not reveal any statistically significant difference between two suture materials used with respect to the diameter of the connective tissue inflammatory infiltrate $(\mathrm{P}=0.321)$. However, it was observed that the inflammatory infiltrate was greater around the multifilament sutures silk compared to monofilament m-PTFE. The inflammatory infiltrate was denser perisuturally around the multifilament sutures with lesser density of collagen fibres and other connective tissue elements per unit area. The results are similar to various other studies which have concluded that there is more pronounced tissue inflammation around multifilament sutures. A possible explanation for this occurrence could be the Wicking effect of the braided sutures which allow bacteria to gain access to the deeper tissues leading to greater inflammation. Among the monofilament suture, least amount of inflammatory infiltrate adjacent to the suture track is observed. ${ }^{17}$

\section{Proportion of Inflammatory Cells to Epithelial Cells}

It is ranged from $0.2 \mathrm{~mm}$ to $2 \mathrm{~mm}$ in Silk group and from $0 \mathrm{~mm}$ to $1.6 \mathrm{~mm}$ in $\mathrm{m}$-PTFE group. Statistically no significant difference was detected between the two suture materials used in relation to the proportion of inflammatory cells to epithelial cells $(\mathrm{P}=0.823)$. It was observed that the proportion of inflammatory cells to epithelial cells was higher in silk sutures because the proportion of bacterial adherence and inflammation was increased in braided sutures compared to monofilament sutures. This was in accordance with the study done by Leknes et al. ${ }^{13}$ Studies have concluded that there is more pronounced tissue inflammation around multifilament sutures which may be attributed to their Wicking effect. ${ }^{13}$ Studies also indicate that the multifilament sutures are more prone to bacterial adherence than monofilament surure. ${ }^{19}$

In a study given by Leknes et al. mPTFE sutures showed reduced inflammation and greater wound repair at 7 and 10 days compared to silk. This should attribute to the absence of absorption properties. ${ }^{10}$

\section{CONCLUSIONS}

Though the clinical and histological parameters are statistically non-significant, m-polytetrafluoroethylene has shown better results compared to silk.

Data sharing statement provided by the authors is available with the full text of this article at jemds.com.

Financial or other competing interests: None. 
Disclosure forms provided by the authors are available with the full text of this article at jemds.com.

\section{REFERENCES}

[1] Lilly GE. Reaction of oral tissues to suture materials. Oral Surg Oral Med Oral Pathol 1968;26(1):128-33.

[2] Pillai CKS, Sharma CP. Absorbable polymeric surgical sutures: chemistry, production, properties, biodegradibility and performance. J BiomaterAppl 2010;25(4):291-366.

[3] Madsen ET. An experimental and clinical evaluation of surgical suture materials. III. SurgGynecolObstet 1958;106(2):216-24.

[4] Wiksejo UM, Nilveus RE, Selvig KA. Significance of early healing events on periodontal repair: a review. J Periodontal 1992;63(3):158-65.

[5] Selvig KA, Biagiotti GR, Leknes KN, et al. Oral tissue reactions to suture materials. Int J Periodontics Restorative Dent 1998;18(5):474-87.

[6] Everett WG. Suture materials in general surgery. ProgSurg 1970;8:14-37.

[7] Edlich RF, Panek PH, RodeheaverGT, et al. Physical and chemical configuration of sutures in the development of surgical infection. Ann Surg 1973;177(6):679-88.

[8] Karaca E, Hockenberger AS, YildizH.Investigating changes in mechanical properties and tissue reaction of silk, polyster, polyamide and polypropylene sutures in vivi. Textile ResearchJournal 2005;75(4):297-303.

[9] Yaltirik M, DedeogluK, Bilgic B, et al. Comparison of four different suture materials in soft tissue of rats. Oral Dis 2003;9(6):284-86.
[10] Macht SD, Krizek TJ. Sutures and suturing-current concepts. J Oral Surg 1977 8;36(9):710-3.

[11] Kudur MH, Pai SB, Sripathi H, et al. Sutures and suturing techniques in skin closure. Indian J DermatolVnereolLeprol 2009;75(4):425-34.

[12] Choi H,Chae H. Comparison of E.Coli infiltration between new synthetic absorbable sutures. J Korean SurgSoc2009;77:1-6.

[13] RiberioCMB,DaSilva Junior VA, Da Silva Neto JC, et al. Clinical and histopathological study of tissue reactivity to monofilament suture materials: nylon and poliglecaprone 25 in rats. Acta Cir Bras 2005;20(4):284-91.

[14] Leknes KN, Roynstrand IT, Selvig KA. Human gingival tissue reactions to silk and expanded polytetrafluoroethylene sutures. J Periodontal 2005;76(1):34-42.

[15] Tiyek I, Gemci R, Turkoglu S. Comparison of physical properties of sutures in medical liquids. Int J PhysSci 2011;6(8):2158-68.

[16] Lilly GE, Osbon DB, Hutchinson RA, et al. Clinical and bacteriological aspects of polyglycolic acid sutures. J Oral Surg1973;31(2):103-5.

[17] Parirokh M, Asgary S, Eghbal MJ, et al. Ascanning electron microscope study of plaque accumulation on silk and PVDF suture materials in oral mucosa. IntEndod J 2004;37(11):776-81.

[18] Racey GL, Wallace WR, Cavalaris CJ, et al. Comparison of a polyglycolic-poylactic suture to black silk and plain catgut in human oral tissues. J Oral Surg 1978;36(10):766-70.

[19] Katz S, Izhar M, Mirelman D. Bacterial adherence to surgical sutures. A possible factor in suture induced infection. Ann Surg 1981;194(1):35-41. 